\title{
Monozygotic Triplets: Concordance and Discordance for Cleft Lip and Palate / Twin Research Reviews: Depression in Mothers of Multiples; Depression in Mothers and Fathers of ART Conceived Multiples; Epigenetic Differences in Monozygotic Twins; Congenital Anomalies in Surviving Twins / Headlines $\times$ Two: Twin Chefs; The World's Largest Twin Registry; Twin Table Tennis Champions
}

\author{
Nancy L. Segal \\ California State University, United States of America
}

$\Lambda$ review of twin research on cleft lip and palate is presented. This information is accompanied by a look at the lives of young monozygotic (MZ) male triplets concordant for cleft lip, but discordant for the type and placement of the cleft and for the presence of cleft palate. Research on depression in mothers and fathers of twins conceived naturally and by artificial reproductive techniques follows. Current findings and implications of epigenetic differences in MZ twins are also summarized. Interesting life history events surrounding MZ twin chefs and table tennis players, as well as plans to construct the world's largest twin registry, are presented in the final section.

\section{Monozygotic Triplets: Concordance and Discordance for Cleft Lip and Palate}

In February 2009 I received a message from Jenn Seager, mother of young MZ male triplets. She described a harrowing pregnancy that included bloating, spotting and a 15-week diagnosis of monozygotic/triamniotic triplets with cleft lip (all three boys) and cleft palate (one boy). When the triplets were born at nearly 30 weeks gestation it was determined that each baby's cleft was in a different location, and that each showed the trait to a differing degree. Baby $\mathrm{T}$ had a complete unilateral cleft on the left, Baby $\mathrm{O}$ had an incomplete unilateral cleft on the right, and Baby A had an incomplete bilateral cleft in the middle; Baby $\mathrm{T}$ also had cleft palate. Interestingly, the position of their clefts coincided with their positions in the womb. Their geneticist informed the family that this was the world's first case of MZ triplets with cleft lip/palate.

Cleft lip and palate affect approximately 1/700 newborns and may be associated with either genetic or nongenetic factors (Casci, 2002). These facial characteristics occur in one of two syndromes, Van der Woude Syndrome (VWS) and popliteal pterygium (PPS). PPS individuals also suffer from abnormalities of the skin and genitals. The triplets showed no other physical abnormalities, with the exception of an atrial septal defect in Baby A that closed naturally. However, DNA testing revealed that they did not have VWS. In fact, the origin of the triplets' clefts is somewhat uncertain. Clefts have never appeared in their mother's family. The triplets' father was adopted, and while he was able to confirm the absence of clefts in his mother's biological family, he has never located his biological father.

A genetic basis to cleft lip and palate has been established. A gene linked to VWS and PPS was identified by Kondo et al. (2002); one member of a discordant MZ twin pair showed a mutation on the IFR6 gene. VWS and PPS are allelic, but are associated with different mutations. Mansilla et al. (2005)

Address for correspondence: Nancy L. Segal, Department of Psychology, California State University, Fullerton, CA 92834, USA. E-mail: nsegal@Exchange.FULLERTON.EDU 


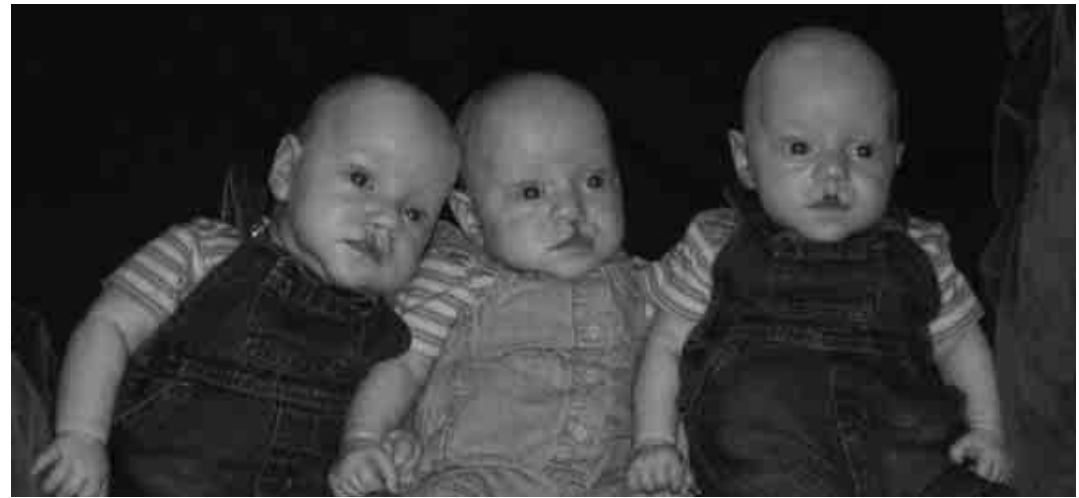

Figure 1

Seager triplets, aged 23 weeks. Photo courtesy Jenn Seager.

performed DNA sequencing of 18 candidate genes in $\mathrm{MZ}$ and $\mathrm{DZ}$ twin pairs with cleft lip, with or without cleft palate. They did not detect etiologic variations between discordant co-twins. However, they encouraged continued DNA screening of MZ twins discordant for complex conditions as a way to identify relevant differences.

More recently, Kimani et al. (2007) compared X-inactivation patterns between discordant female $\mathrm{MZ}$ co-twins ( $n=8$ pairs) and non-twin sisters $(n=$ 52 pairs). Significant differences in skewing were not detected within the twin pairs. In contrast, borderline significant differences were detected within the sister pairs, with the greatest differences occurring between sisters in which cleft lip co-occurred with cleft palate. Greater skewing was found in the unaffected sisters, an atypical finding since greater skewing is usually associated with abnormality.

\section{Breastfeeding the Triplets}

Breastfeeding poses considerable challenge to higher order mothers of multiples. It was even more difficult in the case of the young triplets. In an informative and moving essay, their mother recalls the early frustration and eventual determination that made breastfeeding her boys possible (Seager, 2007a). Initially, she was unable to obtain information as to the feasibility of breastfeeding her children, either from physicians or from other parents. Still in the hospital, she attempted unsuccessfully to pump her breast milk, despite discouragement from a nurse who implied that such efforts would be 'fruitless.' Meanwhile, the babies

Figure 2 were being fed small amounts of a sugar solution.

Jenn returned home, leaving the premature triplets in the hospital. Another nurse (also a mother of twins) advised her to place a photo of the boys in front of her and to try again. This time it worked, and she began a regimen of pumping and delivering the milk to the hospital at regular intervals. Then, prompted by a lactation consultant, she attempted to actually breast feed the babies. This proved impossible for the baby with cleft lip and palate since he could not create the necessary suction; he continued to receive the pumped milk. However, the process worked beautifully with the other two boys. When they reached 22 months of age, all three had surpassed their developmental milestones. The photographs in Figures 1 and 2 and show the triplets at age 23 weeks and at 4 years.

Jenn Seager's experience is important for researchers, parents and physicians to hear. When I interviewed her she spoke again about the time that she was first able to pump milk. She wonders whether the photograph of the boys may have triggered maternal feelings that allowed the milk to flow. I asked her why other parents were not helpful in this regard; she believes that they were discouraged from trying to breastfeed their children as she had been. Furthermore, she was not allowed to touch the babies until 3 hours after they were born, compounding her difficult situation (Seager, 2007b). Touching them would have created stimulation, causing them to burn calories.

The triplets' clefts have been surgically repaired and are hardly noticeable in Triplets A and O. The cleft is more apparent in Triplet $\mathrm{T}$, so he has had to weather some unkind remarks from other children. Some additional surgeries in the future will be beneficial in this regard. The three boys are terrific friends, and while they fight occasionally they quickly defend each other if anyone comes between them - it is usually Triplet $\mathrm{T}$ who takes charge. The three boys are right-handed, but they all use their left hand for selected activities, such as hockey. When they start school next year they will be in the same class and play on the same hockey team.

Jenn Seager's original essays deserve to be read in full. The complete references are provided in the list at the end of this article. She has already begun answering questions from concerned families who have contacted her directly - no one who can do that better.

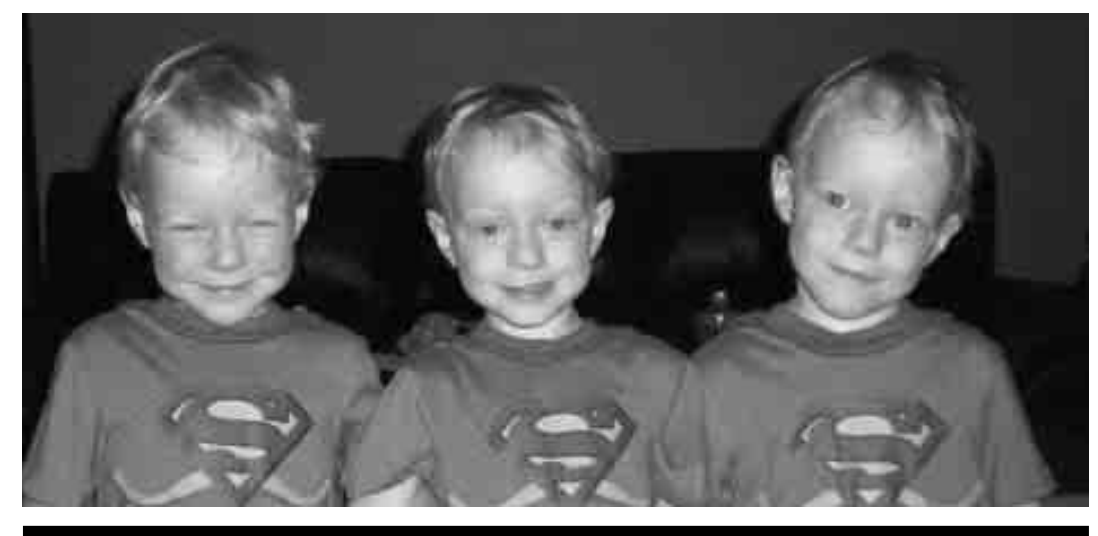

Seager triplets, aged 4 years. Photo courtesy Jenn Seager. 


\section{Twin Research Reviews}

\section{Depression in Mothers of Multiples}

Multiple births appear to increase the risk of depressive symptoms by $43 \%$ in mothers assessed 9 months after giving birth. Choi et al. (2009) from Johns Hopkins University measured depressive symptoms in mothers identified via the Early Childhood Longitudinal Study - Birth Cohort. This nationally representative sample includes children born in 2001. Severe depression was detected among 19\% of the multiple birth mothers and $16 \%$ of the singleton mothers. It is disturbing that only $27 \%$ of the mothers (who had delivered either twins or non-twins) sought psychological assistance for their depression. The authors stressed the need for concerted efforts to educate new families about the potential for depressive symptoms.

I would urge all new multiple birth parents to join mothers of twins clubs and other organizations specifically targeted to issues raised by twins and other multiples. These clubs, which operate at local, state and national levels, provide immediate support and information for their members.

\section{Depression in Mothers and Father of ART (Assisted Reproductive Technology)- Conceived Multiples}

This study confirms some findings summarized in the previous review. The psychological well-being of four groups of parents was compared by Finnish investigators Vilska et al.
(2009). The four study groups included mothers and father of twins and mothers and father of non-twins, who either conceived spontaneously or via ART. The study was longitudinal in design, with data collected by questionnaire at the end of the second trimester of pregnancy, when the children were 2 months old and when the children were 1 year old. Depressive symptoms were found with greater frequency among parents of twins than among parents of non-twins, irrespective of method of conception. Parity and various child-related factors, such as birthweight and prematurity, did not affect mothers' behaviors. However, prematurity negatively affected social functioning in father of twins whose children were conceived naturally.

\section{Epigenetic Differences in Monozygotic Twins}

Haque et al. (2009) deliver a superb overview of current findings in epigenetics and what they mean for the future of psychiatric twin research. They make the point that Galton's early insight into twin studies - that twins allow separation of the effects of nature and nurture - is no longer tenable as it stands. Instead, Galton's view requires revision to cover the full range of non-genetic sources of variance underlying $M Z$ co-twin differences. According to the authors, 'The new paradigm is not one of nature versus nurture, but of a complex and dynamic interaction between DNA sequence, epigenetic
DNA modifications, gene expression, and environmental factors that all combine to influence phenotype' (pp. 136-137).

The differential onset and expression of schizophrenia and bipolar disorder in some $M Z$ twin pairs may be better understood in light of this new view. Diagnoses of these disorders in non-twins and their relatives can benefit considerably from these efforts.

\section{Congenital Anomalies in Surviving Twins}

The increased frequency of congenital anomalies in twins, relative to nontwins, is well established. However, less is known about the implications of the fetal loss of one twin for the co-twin survivor. A new study by Pharoah et al. (2009) examined relevant data from the Northern Multiple Pregnancy Registry and Northern Congenital Abnormality Survey, gathered between 1998-2004. It was determined that the early loss of a conceptus raises the risk of a congenital anomaly in surviving twins. Congenital anomalies were observed in 331.2/10,000 twin births, as compared with 206.1/10,000 non-twin births. The frequency of birth problems rose to $381 / 0 / 10,000$ births among triplets. The investigators called for the linking of multiple birth and congenital anomaly registers to obtain better frequencies of congenital anomalies in twin and non-twin populations, so as to further progress in this area.

\section{Headlines $\times$ Two}

\section{Twin Chefs}

The Russian Tea Room is a New York City treasure when it comes to restaurants. It has recently been staffed by 27-year-old twins, Brice and Peter (Petrous) Moldovan (Buckley, 2009). The identical brothers were born in France and have French and Romanian ancestry. They began working as chefs in their parents' brasserie when they were children, and entered culinary school at the age of thirteen. They share a close social relationship, but have their own families and admit to having created their own signature dish — beef stroganoff for Peter and 'the 1917' (a specialty drink) for Brice.

\section{The World's Largest Twin Registry}

The largest twin registry in the world, to be known as TwinBank, is being planned in the United Kingdom (Holden, 2009). Efforts toward securing funding for this project are under the direction of Drs. Robert Plomin and Tim Spector. The ultimate aim is to perform DNA testing on 300,000 twin pairs. Such information will afford new insights into the origins and progress of genetically influenced diseases and other medical conditions. 


\section{Twin Table Tennis Champions}

Identical 14-year-old twins, Brandon and Brad Belle of Brooklyn, New York, have distinguished themselves as champion table tennis players in a very short time. The twins moved to Brooklyn from Guyana in 2007 and began playing table tennis shortly thereafter. Their coach recalls that they went from being nonplayers to tournament competitors in only 3 months. They began to win tournaments four months after that. The twins are physically matched, except for their hand preference - Brandon is left-handed and Brad is right-handed. Their next goal is to participate in the Olympic trials in January 2012.

\section{$\overline{\text { References }}$}

Buckley, C. (2009, 20 April). Culinary twins, rarely separated since birth. New York Times.

Casci, T. (2002). A twin approach to disease. Nature Reviews (Genetics), 3, 732.

Choi, Y., Bishai, D., \& Minokvitz, C. (2009). Multiple births are a risk factor for postpartum maternal depressive symptoms. Pediatrics, 123, 1208-1216.
Haque, F. N., Gottesman, I. I., \& Wong, A. H. C. (2009). Not really identical: Epigenetic differences in monozygotic twins and implications for twin studies in psychiatry. American Journal of Medical Genetics Part C (Seminars in Medical Genetics), 151C, 136-141.

Holden, C. (2009). 'Banking on Twins.' Science, 324, 571.

Kimani, J. W., Shi, M., Daack-Hirsch, S., Christenen, K., Moretti-Ferreira, D., Marazita, M. L., Field, L. L., Canady, J. W., Murray, J. C. (2007). XChromosome inactivation patterns in monosygotic twins and sib pairs discordant for nonsyndromic cleft lip and/or palate. American Journal of Medical Genetics Part A, 143A, 32673272.

Kondo, S., Schutte, B. C., Richardson, R. J., Bjork, B. C., Knight, A. S., \& Watanabe, Y. (2002). Mutations in IRF6 cause Van der Woude and popliteal pteryglum syndromes. Nature Genetics, 32, 285-289.

Mansilla, M. A., Kimani, J., Mitchell, L. E., Christensen, K., Boomsma, D. I., Daack-Hirsh,S., Nepomucena, B., Wyszynski, D. F., Felix, T. M., Martin, N. G., \& Murray, J. C. (2005). Discordant MZ twins with cleft lip and palate: A model for identifying genes in complex traits. Twin Research and Human Genetics, 8, 39-46.

NYDailyNews.com (2009, 17 April). 'Meet Brooklyn's table tennis terrors.' Available at www.the2012londonolympics.com/ forum/showthread.php?t=14069.

Pharoah, P. O. D., Glinianaia, S. V., \& Rankin, J. (2009). Congenital anomalies in multiple births after early loss of a conceptus. Human Reproduction, 24, 726-731.

Seager, J. (2007a). 'Breastfeeding miracle.' Mothering, 142, 66-69. See also http://www.mothering.com/articles/ne w_baby/breastfeeding/breastfeedingmiracle.html

Seagher, J. (2007b). Beautiful chaos. Canadian Living, November, 97-102.

Vilska, S., Unkila-Kailo, L., Punamaki, R.L., Poikkeus, P., Repokari, L., Sinkkonen, J., Tiitinen, A., \& Tulppala, M. (2009). Mental health of mothers and fathers of twins conceived via assisted reproduction treatment: A 1 -year prospective study. Human Reproduction, 24, 367-377. Heterotaxy syndrome with mirror-image anomalies in identical twins. Congenital Heart Disease, 4, 50-53.

\section{Additional Abstract from the Genes for Health Meeting, Incorporating the Inaugural GRaPH-Int Conference and the 33rd HGSA Annual Scientific Meeting Fremantle, Australia, May 3-6, 2009}

\section{HIGH THROUGHPUT SCREENING FOR THE PHARMACOLOGICAL THERAPY OF FRIEDREICH ATAXIA [192]}

L. Li', S. van den Hengel' , J. Cook', P.A. loannou ${ }^{2,3}$, M. B. Delatycki', and J. P. Sarsero ${ }^{1,2,3}$

Bruce Lefroy Centre for Genetic Health Research, Murdoch Children's Research Institute, Royal Children's Hospital, Victoria, Australia

2 Cell and Gene Therapy, Murdoch Children's Research Institute, Royal Children's Hospital, Victoria, Australia

Department of Paediatrics, University of Melbourne, Murdoch Children's Research Institute, Royal Children's Hospital, Victoria, Australia

Friedreich ataxia (FRDA) is characterized by neurodegeneration and cardiomyopathy. The presence of a GAA trinucleotide repeat expansion in the first intron of the FXN gene results in the inhibition of gene expression and an insufficiency of the mitochondrial protein, frataxin. There is a correlation between expansion length, the amount of residual frataxin and the severity of disease. As the coding sequence is unaltered, pharmacological upregulation of FXN expression may restore frataxin to therapeutic levels in patients. To facilitate screening of compounds that modulate FXN expression in a physiologically relevant manner, we have established a genomic reporter assay consisting of stable HeLa cells containing an FXNEGFP fusion construct (in-frame fusion of the EGFP gene with the entire normal human genomic FXN locus on a BAC clone). The cell line was used to establish a fluorometric cellular assay for use in high throughput screening (HTS) procedures. A small chemical library of FDA-approved compounds and natural extracts has been screened and analysed. Compound hits identified by HTS have been further evaluated by flow cytometry in the cellular genomic reporter assay. The effects on FXN mRNA and frataxin protein levels have been measured in cell lines derived from individuals with FRDA. Any compound that specifically increases frataxin levels by severalfold in FRDA patients could serve as a potential pharmacological therapy for Friedreich ataxia. 